\title{
Characterization of Fusarium Head Blight Resistance and Deoxynivalenol Accumulation in Hulled and Hulless Winter Barley
}

Gregory Berger, Department of Crop, Soil, and Environmental Sciences, University of Arkansas, Rice Research and Extension Center, Stuttgart 72160; Andrew Green, Department of Agronomy, Kansas State University, Manhattan 66506; Piyum Khatibi, Department of Plant Pathology, Physiology, and Weed Science, Wynse Brooks, Department of Crop and Soil Environmental Sciences, and Luciana Rosso, Department of Crop and Soil Environmental Sciences, Virginia Tech, Blacksburg 24061; Shuyu Liu, Texas AgriLife Research, Texas A\&M, Amarillo 79106; Shiaoman Chao, United States Department of Agriculture-Agricultural Research Service Biosciences Research Lab, Fargo, ND 58102; and Carl Griffey, Department of Crop and Soil Environmental Sciences, and David Schmale III, Department of Plant Pathology, Physiology, and Weed Science, Virginia Tech

\begin{abstract}
Berger, G., Green, A., Khatibi, P., Brooks, W., Rosso, L., Liu, S., Chao, S., Griffey, C., and Schmale, D., III. 2014. Characterization of Fusarium head blight resistance and deoxynivalenol accumulation in hulled and hulless winter barley. Plant Dis. 98:599-606.

Fusarium head blight (FHB), caused by Fusarium graminearum, is one of the most serious diseases impacting the U.S. barley (Hordeum vulgare) industry. The mycotoxin deoxynivalenol (DON), produced by the pathogen, renders grain unmarketable if concentrations exceed threshold values set for end-use markets. Development of cultivars with improved FHB resistance and reduced DON accumulation is necessary to ensure minimal losses. Elite hulled and hulless genotypes developed by the Virginia Tech winter barley breeding program were screened in inoculated, mist-irrigated FHB nurseries over 2 years at two locations in Virginia to validate resistance levels over years and locations. Re-

sults demonstrated that barley genotypes varied significantly for resistance to FHB and DON accumulation. The hulled 'Nomini', hulless 'Eve', and hulless line VA06H-48 were consistently resistant across locations to both FHB and DON accumulation. Screening the genotypes with molecular markers on chromosomes $2 \mathrm{H}$ and $6 \mathrm{H}$ for $\mathrm{FHB}$ and DON revealed quantitative trait loci regions which may confer resistance in the Virginia Tech germplasm. Ongoing and future work with mapping populations seeks to identify novel regions for resistance to FHB and DON accumulation unique to the Virginia Tech breeding program.
\end{abstract}

Winter barley (Hordeum vulgare L.) genotypes developed in Virginia are widely adapted to diverse regions in the eastern United States having humid climates and variable rainfall patterns (42). One of the major pathogens plaguing the U.S. barley industry is Fusarium head blight (FHB), caused by Fusarium graminearum. The mycotoxin deoxynivalenol (DON), produced by the pathogen, renders grain unmarketable if concentrations exceed threshold values set for end-use markets. Although hulled barley grown in the mid-Atlantic region has historically been utilized as animal feed (3), use of both hulled and hulless barley as a potential fuel ethanol feedstock has garnered recent interest (8). The hulless phenotype is controlled by a single recessive gene referred to as the nud locus on chromosome $7 \mathrm{H}$ (41). Hulled and hulless genotypes differ significantly in grain and kernel weight, starch, $\beta$-glucan, and oil and ash content (13). Hulless barley genotypes have higher starch concentrations and lower oil and ash concentrations than hulled genotypes (13). Selection of hulled and hulless barley geno-

Corresponding author: G. Berger, E-mail: glberger@uark.edu

For correspondence about the specific genotypes in this work, please contact C. A. Griffey, E-mail: cgriffey@ vt.edu. For correspondence about the DON testing in this work, please contact D. Schmale, E-mail: dschmale@vt.edu.

* The $\boldsymbol{e}$-Xtra logo stands for "electronic extra" and indicates that a supplementary table is available in the online edition.

Any opinions, findings, conclusions, or recommendations expressed in this publication are those of the authors and do not necessarily reflect the views of the United States Department of Agriculture or the Virginia Small Grains Board.

Accepted for publication 29 October 2013.

http://dx.doi.org/10.1094/PDIS-05-13-0479-RE

(C) 2014 The American Phytopathological Society types with high starch and protein levels will help facilitate development of the next generation of barley cultivars suitable for both feed and fuel ethanol production (13).

Recent estimates suggest that the United States can produce two billion gallons of fuel ethanol per year from barley alone (35). Distiller's dried grains with solubles (DDGS) is a nutrient-rich byproduct of the ethanol fuel fermentation process that can be used as animal feed or to enrich human food products (14). Fuel ethanol producers rely on the sale of DDGS to bolster profits (23). In a series of small-scale fuel ethanol fermentation studies, DON levels were concentrated 1.6 to 8.2 times in DDGS when compared with ground grain, depending on the barley genotype used in the fermentation mash (21). Although the percentage increase in DON concentration in DDGS versus initial grain was highest for genotypes having low initial DON levels, DDGS produced from these genotypes had the lowest overall DON concentrations (21).

Considering the importance of DDGS to fuel ethanol fermentation plants, breeding for FHB resistance is a critical objective in cultivar development. A key step in breeding for FHB resistance is characterizing levels of FHB and DON resistance in breeding material. Two types of FHB resistance described in wheat include type I resistance, which is a measure of initial pathogen infection, and type II resistance, which is a measure of the spread of the pathogen in the spike after initial infection (36). Although type I resistance is relevant for barley, type II resistance is not measured as frequently because pathogen movement up and down the spike is not often observed (32). Previous studies have characterized barley as having varying levels of type I resistance and innate high levels of type II resistance (38). Resistance to DON production has also been proposed as a mechanism of resistance in wheat (38). Barley breeders focus on screening elite material for FHB and DON accumulation to identify genotypes with improved levels of resistance (32).

Regions in the barley genome associated with FHB resistance have been characterized in spring barley. Quantitative trait loci (QTL) contributing to FHB resistance have been identified on all 
seven barley chromosomes (24). QTL for FHB resistance on chromosomes $2 \mathrm{H}$ and $6 \mathrm{H}$ have most commonly been identified among diverse germplasm $(11,12,15-17,24,25,34,45)$. The spring barley 'Chevron' (CI1111), introduced from Switzerland, has been widely used as a source of resistance to FHB and kernel discoloration in the Midwest (12). De la Pena et al. (12) identified 10 QTL for FHB resistance, 11 QTL for DON accumulation, and 4 QTL for kernel discoloration in a population derived from Chevron and the elite breeding line M69. A major QTL located on chromosome $2 \mathrm{H} \mathrm{ex}-$ plained $13.5 \%$ of the variation for FHB severity (SEV) and DON accumulation; however, resistance was linked in coupling to late heading date (12). Mesfin et al. (25) used a population derived from a cross between 'Fredrickson' (two-rowed) and 'Stander' (six-rowed) to determine the effect of heading date and the tworowed (Vrsl) phenotype on FHB resistance. They detected three regions on chromosome $2 \mathrm{H}$ associated with $\mathrm{FHB}$ resistance, with two of the regions being associated with DON accumulation (25). Among these QTL, one also was associated with heading date and another was associated with the Vrsl locus (25). A higher level of resistance to FHB has been observed for two-rowed compared with six-rowed barley (39). Nduulu et al. (28) determined that the relationship between FHB SEV, DON concentration, and heading date for a coincidental QTL designated as $\operatorname{Qrgz}-2 \mathrm{H}-8$ (derived from Chevron) was likely due to tightly linked genes and not pleiotropy. Canci et al. (9) identified a large effect of QTL on chromosome $6 \mathrm{H}$, which was estimated to decrease FHB SEV and kernel discoloration by 56 and $73 \%$ and increase heading date by 0.5 days. Molecular markers developed in spring barley mapping studies have the potential to be used to identify regions conferring resistance in winter barley.

Khatibi et al. (20) reported variation for resistance to FHB and DON accumulation in the Virginia Tech winter barley germplasm. Variation in flowering date, FHB incidence (INC), FHB index (IND), and DON accumulation were significant among hulled and hulless genotypes (20). However, only a few genotypes were tested over multiple years and many genotypes were only evaluated at a single location (20). In addition, IND and DON accumulation were low in 3 of the 5 years, thus making it difficult to determine the stability of resistance (20). INC and IND were only strongly correlated with DON accumulation in 2 of the 5 years (20). Therefore, further validation of host response and stability of reaction to FHB of putatively resistant and susceptible genotypes in additional environments and under more extensive disease epidemic conditions was deemed necessary to confirm levels of resistance to FHB and DON in winter barley.
Further characterization of FHB resistance in winter barley genotypes using molecular markers also will facilitate the elucidation of putative QTL for FHB resistance. Pedigree analysis suggests that sources of resistance within Virginia Tech barley genotypes may be unique compared with those derived from Chevron $(9,28)$ and Fredrickson (25). Markers associated with novel sources of resistance to $\mathrm{FHB}$ and DON accumulation would be of great value in developing new genotypes and selecting for FHB resistance. The specific objectives of the study were to (i) validate host response to FHB and its stability in resistant and susceptible genotypes of winter barley over 2 years at two diverse locations, (ii) determine levels of resistance to DON accumulation in winter barley genotypes, and (iii) use phenotypic and genotypic data to aid in the selection of parents for traditional and marker-assisted breeding programs, and for development of mapping populations for FHB resistance and DON accumulation.

\section{Materials and Methods}

Field evaluations. Nine hulled and nine hulless winter barley genotypes (Table 1), including three putatively resistant, moderately resistant, and susceptible genotypes identified in a previous study (20), were selected from the Virginia Tech barley breeding program to further characterize and validate their response to FHB over 2 years at two locations. Genotypes were planted in a randomized complete block with two replications in mist-irrigated nurseries at Blacksburg, VA (Guernsey silt loam, $37^{\circ} 12^{\prime} \mathrm{N}, 80^{\circ} 34^{\prime} \mathrm{W}$, $531.5 \mathrm{~m}$ in elevation) and Mt. Holly, VA (State fine sandy loam, $38^{\circ} 5^{\prime} \mathrm{N}, 76^{\circ} 44^{\prime} \mathrm{W}, 12 \mathrm{~m}$ in elevation) during the $2009-10$ and 2010 11 growing seasons. Each experimental unit consisted of a seven-row plot planted at $13.4 \mathrm{~m}$ in length, with $15.2 \mathrm{~cm}$ of spacing between rows and a harvested plot area of $19 \mathrm{~m}^{2}$, to produce sufficient grain for analysis of DON concentration in barley grain and for a detoxification study (21). F. graminearum-colonized corn (Zea mays) kernels were applied to plots at the boot stage in both locations during all years of the study, and plots at Blacksburg were spray inoculated using macroconidia $(50,000$ spores $/ \mathrm{ml})$ applied at $50 \%$ heading stage $(10,20)$. Isolates used in the study, mycotoxin genotype, and source location are as described by Khatibi et al. (20). Overhead mist irrigation was applied at 1-h intervals from 8:00 to 9:00 a.m. and from 4:00 to 5:00 p.m. daily for 3 weeks, except during precipitation events $(10,20)$. Plots were harvested at maturity ( $\leq 16 \%$ moisture) using Wintersteiger plot combines (Wintersteiger) with the fan speed set at a low setting to reduce loss of scabby grain.

Weather data. Temperature and rainfall data were collected at the Kentland Research farm and Warsaw Eastern Virginia Agricul-

Table 1. Barley genotypes tested for Fusarium head blight (FHB) resistance in Blacksburg and Mt. Holly, VA during the 2009-10 and 2010-11 growing seasons

\begin{tabular}{|c|c|c|c|c|}
\hline Genotype & Type & Pedigree & Year of release $^{y}$ & Classification $^{\mathrm{z}}$ \\
\hline Nomini & Hulled & Boone/Henry//VA77-12-41 & $1991(40)$ & $\mathrm{R}$ \\
\hline Callao & Hulled & Boone/Henry//Sussex & $1994(33)$ & MS \\
\hline Price & Hulled & Callao/SC830366 & $2002(6)$ & $\mathrm{S}$ \\
\hline Thoroughbred & Hulled & VA90-44-110/Plaisant & $2003(5)$ & $\mathrm{S}$ \\
\hline Atlantic & Hulled & VA97B-176/VA92-42-279 & 2011 & $\mathrm{~S}$ \\
\hline VA04B-125 & Hulled & VA97B-178/VA97B-283 & Experimental & $\mathrm{S}$ \\
\hline VA06B-32 & Hulled & VA98B-112/VA99B-172 & Experimental & MS \\
\hline VA07B-52 & Hulled & VA97B-176//VA96B-113/VA96B-70 & Experimental & $\mathrm{S}$ \\
\hline VA96-44-304 & Hulled & Callao/VA89-41-6 & Experimental & $\mathrm{S}$ \\
\hline Doyce & Hulless & CMB79-54//VA90-42-56/VA90-42-22/3/Pamunkey/4/H-585 & $2003(7)$ & $\mathrm{S}$ \\
\hline Eve & Hulless & SC 860974/VA94-42-13 & $2007(9)$ & $\mathrm{R}$ \\
\hline Dan & Hulless & VA96-41-17/ SC872143 & $2009(8)$ & $\mathrm{S}$ \\
\hline VA05H-59 & Hulless & VA96-41-35/VA95-41-26//VA92-42-46/3/SC860934 & Experimental & $\mathrm{S}$ \\
\hline VA06H-142 & Hulless & Thoroughbred/Doyce & Experimental & MS \\
\hline VA06H-25 & Hulless & Thoroughbred/SC 872143 & Experimental & $\mathrm{S}$ \\
\hline VA06H-31 & Hulless & Thoroughbred/SC 872143 & Experimental & MS \\
\hline VA06H-48 & Hulless & Thoroughbred//VA96-41-25/SC890573 & Experimental & $\mathrm{R}$ \\
\hline VA07H-35WS & Hulless & Thoroughbred/SC 872143 & Experimental & $\mathrm{S}$ \\
\hline
\end{tabular}

${ }^{y}$ Cultivars released by the Virginia Tech barley breeding program are indicated by their year of release and reference; experimental genotypes are designated as such.

${ }^{\mathrm{z}}$ Resistance classification based on deoxynivalenol (DON) accumulation in Mt. Holly, VA; R = resistant, MS = moderately susceptible, and S = susceptible . 
tural Research Center (EVAREC). The Warsaw EVAREC weather station $\left(37^{\circ} 59^{\prime} \mathrm{N}, 76^{\circ} 46^{\prime} \mathrm{W}, 40.5 \mathrm{~m}\right.$ in elevation) is the nearest (11 miles from the field site) available weather station to the Mt. Holly field location. In Warsaw, minimum and maximum daily temperatures and total rainfall for $24-\mathrm{h}$ periods were recorded. Hourly temperature and rainfall for 24 periods were collected at the Kentland research farm. For both locations, average daily temperatures and total daily rainfall were interpreted and discussed in the results.

FHB INC, SEV, IND, and quantification of DON in grain samples. Plots were rated for INC and SEV to determine FHB resistance. FHB INC, the percentage of diseased heads per 10 random heads sampled at three locations distributed throughout each plot, was measured twice each season (approximately 3 weeks and 4 to 5 weeks after heading). FHB SEV, measured as the percentage of diseased spikelets divided by the total number of spikelets for 30 diseased heads per plot, was determined at the same time as the second FHB INC rating. IND was calculated as (FHB INC $\times$ FHB $\mathrm{SEV}) / 100$ for each genotype and used as a measure of FHB resistance. After harvest, a subsample of grain from each plot was cleaned on a screen cleaner without air which allowed grain to pass through and for removal of plant debris. Subsamples of grain were used for quantification of DON concentration and Fusarium-damaged kernels (FDK), which was determined by counting the number of infected kernels per a random sample of 100 kernels for each genotype. DON concentration was determined in ground whole-grain flour subsamples using gas chromatography and mass spectrometry, as described previously (20).

Molecular marker genotyping. In an effort to elucidate whether QTL for FHB resistance in Virginia Tech's winter barley germplasm are unique, genotypes were screened with markers for QTL Qrgz-2H-8 (28), QFhs.umn-2H.2, QFhs.umn-2H.4, QFhs.umn-2H.5, and QDon.umn-2H.1 (25) located on chromosome $2 \mathrm{H}$. Genotypes also were screened with markers for a QTL located on chromosome $6 \mathrm{H}$ associated with FHB resistance (9). Leaf tissue was harvested at the two-leaf stage from genotypes planted in the study along with check cultivars Chevron (FHB resistant), Fredrickson (FHB resistant), and Stander (FHB susceptible). Leaf tissue was stored at $-80^{\circ} \mathrm{C}$ prior to grinding with a GenoGrinder (Spex CertiPrep). DNA isolation was conducted using an established protocol (33). Direct-labeled primers were used for polymerase chain reaction (PCR) amplifications (29). PCR products were resolved using a previously described method (29). Genotypes were visualized by a 3130xl Genetic Analyzer (Applied Biosystems). Scoring of the genotypes was done manually based on allele size.

Additionally, genotypes were screened for single-nucleotide polymorphism (SNP) markers associated with FHB and DON resistance at the United States Department of Agriculture-Agricultural Research Service Biosciences Research Lab in Fargo, ND. These markers are routinely used for marker-assisted selection (MAS) by Dr. Rich Horsley in the North Dakota State University barley breeding program. The most common source of resistance in his program, 'CIHo 4196', was included as a check in the SNP dataset. Known resistant genotypes Fredrickson and Chevron and susceptible genotypes 'Plaisant' and Stander were included as references. Genotyping protocols were conducted as described previously (2).
Statistical analyses. Normality of data was tested using the PROC UNIVARIATE procedure in SAS (version 9.2; SAS Institute), based on the Shapiro-Wilk test. Grand means and standard error of means were determined using PROC MEANS. Pairwise correlations between FHB INC and IND, DON, and FDK were estimated using PROC CORR. Analysis of variance for all data was tested using PROC GLIMMIX. Year, location, and genotype were treated as fixed effects and location-year, nested within blocks, was treated as a random effect. Mean comparisons for genotype within location were calculated using the means procedure in SAS. The critical value for Tukey's honest significant difference $(\alpha=0.05)$ was calculated manually (44).

\section{Results}

Weather summary. Average daily temperatures for the period from April to June differed across years and locations. This variation is due to distinct differences in elevation between the research farm at Mt. Holly, VA (17 $\mathrm{m}$ in elevation) and the Kentland research farm at Blacksburg, VA (531.5 $\mathrm{m}$ in elevation) and the proximity of Mt. Holly to the Atlantic coast. Overall, Blacksburg had much cooler temperatures $\left(13\right.$ to $23^{\circ} \mathrm{C}$ in 2010 and 13 to $21^{\circ} \mathrm{C}$ in 2011) than Mt. Holly ( 17 to $27^{\circ} \mathrm{C}$ in 2010 and 17 to $25^{\circ} \mathrm{C}$ in 2011) for the period between heading and harvest, when plants are prone to infection, FHB development, and DON accumulation.

Daily rainfall varied greatly across locations. During 2010, Blacksburg $(94.5 \mathrm{~mm})$ and Mt. Holly $(61.9 \mathrm{~mm})$ received heavy natural precipitation events between heading and harvest. During 2011, natural precipitation was higher for both Blacksburg (195.1 $\mathrm{mm}$ ) and Mt. Holly (102.1 mm) during the period between heading and harvest. Infection and FHB development were greater in magnitude at Mt. Holly than Blacksburg in both years, even though mist irrigation was applied twice a day in all test locations to ensure presence of adequate moisture for infection. Higher humidity combined with warmer temperatures at Mt. Holly during both years likely contributed to higher levels of infection and FHB development at this location.

Analysis of variance. The highest mean values for all traits (FHB INC and IND, DON accumulation, and FDK) were obtained from the 2009-10 test at Mt. Holly, while the 2010-11 test at Blacksburg had the lowest mean values (Table 2). During both years, trait means were higher for tests at Mt. Holly than Blacksburg. Most notable were the higher DON concentrations at Mt. Holly (18.6 and $30.4 \mathrm{ppm}$ ) versus Blacksburg (0.87 and $0.93 \mathrm{ppm})$.

Barley genotypes varied significantly $(P \leq 0.05)$ for FHB INC and IND, DON accumulation, and FDK (Table 3). There was a significant genotype-location interaction for FHB INC and IND, DON accumulation, and FDK, thus prohibiting pooling of data over locations. In contrast, FDK was the only trait having a significant genotype-year interaction. The genotype-year interaction can be attributed to a change in magnitude of mean values from 2009 to 2010 for moderately susceptible and susceptible genotypes.

Correlations for FHB INC, FHB IND, DON accumulation, and FDK. Pearson correlation coefficients were calculated across years for each location (Blacksburg and Mt. Holly) separately due to significance of the genotype-location interaction for all traits (Table 4$)$. FHB INC was significantly $(P \leq 0.001)$ and positively correlated with FHB IND at both locations $(r=0.65$ to $0.70, P \leq$ $0.001)$. DON accumulation was significantly $(P \leq 0.05)$ correlated

Table 2. Grand means \pm standard error of means for Fusarium head blight (FHB) incidence (INC) and index (IND), deoxynivalenol (DON) accumulation, and Fusarium-damaged kernels (FDK) for genotypes grown in Blacksburg and Mt. Holly, VA during the 2009-10 and 2010-11 growing seasons

\begin{tabular}{|c|c|c|c|c|}
\hline \multirow[b]{2}{*}{ Parameter } & \multicolumn{2}{|c|}{ Blacksburg } & \multicolumn{2}{|c|}{ Mt. Holly } \\
\hline & 2009-10 & 2010-11 & 2009-10 & 2010-11 \\
\hline Genotypes $(n)$ & 18 & 18 & 18 & 18 \\
\hline FHB INC (\%) & $68.3 \pm 1.3$ & $63.0 \pm 2.4$ & $73.5 \pm 3.6$ & $67.8 \pm 3.2$ \\
\hline FHB IND (\%) & $28.2 \pm 2.4$ & $14.2 \pm 1.4$ & $29.9 \pm 2.7$ & $17.8 \pm 2.0$ \\
\hline DON accumulation (ppm) & $0.93 \pm 0.14$ & $0.87 \pm 0.12$ & $30.4 \pm 4.1$ & $18.6 \pm 1.7$ \\
\hline FDK $(\%)$ & $12.2 \pm 1.2$ & $8.3 \pm 0.5$ & $21.5 \pm 2.7$ & $13.7 \pm 0.9$ \\
\hline
\end{tabular}


with FHB INC and FHB IND at both locations. Correlation values for the Mt. Holly tests $(r=0.60$ and $0.76, P \leq 0.001)$ were numerically higher than those for Blacksburg $(r=0.23, P \leq 0.05$ and $r=$ $0.31, P \leq 0.01)$. Nevertheless, DON accumulation at both locations was positively correlated with FDK $(r=0.35, P \leq 0.01$ in Blacksburg and $r=0.55, P \leq 0.001$ in Mt. Holly).

Resistance to FHB and DON accumulation. Genotypes varied significantly for FHB INC and IND, DON accumulation, and FDK (Table 5). Hulled 'Nomini', hulless 'Eve', and hulless experimental line VA06H-48 consistently had low values for FHB INC and IND and DON accumulation over years at both locations. For Mt. Holly and Blacksburg, these three genotypes had means for FHB INC of 32.5 to $53.3 \%$ and 49.2 to $60.8 \%$, FHB IND from 3.5 to 5.5 and 8.6 to 13.8 , DON accumulation from 5.6 to $6.5 \mathrm{ppm}$ and 0.3 to 0.7 ppm, and FDK from 3.8 to $9.3 \%$ and 5.5 to $9.0 \%$, respectively. In contrast, hulled 'Thoroughbred', previously reported as being re- sistant to FHB and DON accumulation (20), was moderately susceptible to susceptible to FHB, depending on location. For Thoroughbred, FHB INC was 75.0 to $81.7 \%$, FHB IND was 23.4 to 31.4, DON accumulation was 30.5 to $1.6 \mathrm{ppm}$, and FDK was 23.3 to $11.8 \%$ at Mt. Holly and Blacksburg, respectively. Other cultivars and experimental genotypes varied from moderately resistant to susceptible at both locations.

Molecular characterization of genotypes. Initial marker screens indicated that resistant genotypes Nomini and VA06H-48 do not possess the previously reported QTL for FHB resistance shown in Tables 6 and 7. The fragment size in base pairs (146 bp) amplified in Eve for marker GMS03 associated with $\mathrm{Qrgz}-2 \mathrm{H}-8$ is identical to that of Chevron. However, fragment sizes amplified by Eve for flanking markers identifying $\operatorname{Qrgz}-2 \mathrm{H}-8$ were not similar to Chevron (186 to $246 \mathrm{bp}$ ). Fragment sizes amplified in all genotypes except 'Doyce' for marker MWG882 and in all but 'Doyce',

Table 3. Analysis of variance $F$ values for barley genotypes evaluated for Fusarium head blight (FHB) in Blacksburg and Mt. Holly, VA during the 2009-10 and 2010-11 growing seasons ${ }^{\mathrm{z}}$

\begin{tabular}{|c|c|c|c|c|c|}
\hline Effect & df & FHB INC & FHB IND & DON & FDK \\
\hline Year & 1 & $3.48^{\mathrm{NS}}$ & $24.33^{* *}$ & $2.68^{\mathrm{NS}}$ & $31.45^{* *}$ \\
\hline Location & 1 & $2.82^{\mathrm{NS}}$ & $0.96^{\mathrm{NS}}$ & $42.48^{* *}$ & $70.77 * *$ \\
\hline Location $\times$ year & 1 & $0.00^{\mathrm{NS}}$ & $0.14^{\mathrm{NS}}$ & $2.63^{\mathrm{NS}}$ & $0.24^{\mathrm{NS}}$ \\
\hline Location × year (Block) & 4 & & & & \\
\hline Genotype & 17 & $9.42 * * *$ & $10.32 * * *$ & $3.23 * * *$ & $14.22 * * *$ \\
\hline Genotype $\times$ year & 17 & $1.41^{\mathrm{NS}}$ & $1.08^{\mathrm{NS}}$ & $1.22^{\mathrm{NS}}$ & $4.52 * * *$ \\
\hline Genotype $\times$ location & 17 & $1.86^{*}$ & $1.96^{*}$ & $2.99 * * *$ & $3.27 * * *$ \\
\hline Genotype $\times$ location $\times$ year & 17 & $1.70^{\mathrm{NS}}$ & $1.72^{\mathrm{NS}}$ & $1.18^{\mathrm{NS}}$ & $1.75^{\mathrm{NS}}$ \\
\hline Residual & 68 & $\ldots$ & $\ldots$ & $\ldots$ & $\ldots$ \\
\hline Total & 143 & $\ldots$ & $\ldots$ & $\ldots$ & $\ldots$ \\
\hline
\end{tabular}

${ }^{\mathrm{z}}$ FHB incidence (INC) and index (IND), deoxynivalenol (DON), and Fusarium-damaged kernels (FDK); ***, and $* * *=$ significant at $P \leq 0.05,0.01$, and 0.001 , respectively; NS = nonsignificant.

Table 4. Pearson correlations for components of Fusarium head blight (FHB) resistance in barley genotypes evaluated in Blacksburg and Mt. Holly, VA averaged over years ${ }^{\mathrm{z}}$

\begin{tabular}{|c|c|c|c|c|c|c|c|c|}
\hline & \multicolumn{4}{|c|}{ Blacksburg (BBG) } & \multicolumn{4}{|c|}{ Mt. Holly (MH) } \\
\hline & FHB INC & FHB IND & DON & FDK & FHB INC & FHB IND & DON & FDK \\
\hline FHB INC & $\ldots$ & $0.74 * * *$ & $0.23^{*}$ & $0.45^{* * *}$ & $\ldots$ & $0.72 * * *$ & $0.60^{* * *}$ & $0.57 * * *$ \\
\hline FHB IND & $\ldots$ & $\ldots$ & $0.31 * *$ & $0.70 * * *$ & $\ldots$ & $\ldots$ & $0.76^{* * *}$ & $0.65 * * *$ \\
\hline DON & $\ldots$ & $\ldots$ & $\ldots$ & $0.35^{* *}$ & $\ldots$ & $\ldots$ & $\ldots$ & $0.55 * * *$ \\
\hline FDK & $\ldots$ & $\ldots$ & $\ldots$ & $\ldots$ & $\ldots$ & $\ldots$ & $\ldots$ & $\ldots$ \\
\hline
\end{tabular}

${ }^{\mathrm{z}}$ RHB incidence (INC) and index (IND), deoxynivalenol accumulation (DON), and Fusarium-damaged kernels (FDK); $*, * *$, and $* * *=$ significant at $P \leq$ $0.05,0.01$, and 0.001 , respectively.

Table 5. Fusarium head blight (FHB) incidence (INC) and index (IND), deoxynivalenol accumulation (DON), and Fusarium-damaged kernels (FDK) in barley genotypes evaluated at Blacksburg (BBG) and Mt. Holly (MH), VA averaged across years

\begin{tabular}{|c|c|c|c|c|c|c|c|c|c|}
\hline \multirow[b]{2}{*}{ Genotype } & \multirow[b]{2}{*}{ Type } & \multicolumn{2}{|c|}{ FHB INC (\%) } & \multicolumn{2}{|c|}{ FHB IND (value) } & \multicolumn{2}{|c|}{ DON (ppm) } & \multicolumn{2}{|c|}{ FDK $(\%)$} \\
\hline & & MH & BBG & MH & BBG & МH & BBG & МH & BBG \\
\hline Eve & Hulless & 32.5 & 49.2 & 3.5 & 13.8 & 5.6 & 0.3 & 7.3 & 5.5 \\
\hline VA06H-48 & Hulless & 37.5 & 42.5 & 5.0 & 8.6 & 6.5 & 0.3 & 3.8 & 9.0 \\
\hline Nomini & Hulled & 53.3 & 60.8 & 5.5 & 12.0 & 5.8 & 0.7 & 9.3 & 5.5 \\
\hline VA06B-32 & Hulled & 73.3 & 64.2 & 13.3 & 14.6 & 14.1 & 0.5 & 10.0 & 9.5 \\
\hline VA06H-31 & Hulless & 57.5 & 60.0 & 19.0 & 13.3 & 13.5 & 1.1 & 7.8 & 5.0 \\
\hline Callao & Hulled & 74.2 & 64.2 & 19.2 & 14.3 & 16.7 & 0.5 & 11.5 & 7.8 \\
\hline VA07B-52 & Hulled & 69.2 & 60.8 & 20.7 & 14.4 & 25.1 & 0.7 & 12.0 & 6.0 \\
\hline Thoroughbred & Hulled & 75.0 & 81.7 & 23.4 & 31.4 & 30.5 & 1.6 & 23.3 & 11.8 \\
\hline Dan & Hulless & 60.8 & 59.2 & 24.3 & 24.7 & 21.6 & 1.2 & 20.0 & 13.5 \\
\hline VA05H-59 & Hulless & 72.5 & 47.5 & 25.8 & 16.2 & 23.7 & 1.4 & 23.3 & 9.5 \\
\hline Atlantic & Hulled & 82.5 & 72.5 & 26.7 & 20.6 & 34.0 & 0.7 & 13.3 & 7.3 \\
\hline Price & Hulled & 80.0 & 76.7 & 26.8 & 28.2 & 29.9 & 0.3 & 17.5 & 10.8 \\
\hline VA06H-142 & Hulless & 69.2 & 75.8 & 27.2 & 24.8 & 12.5 & 0.5 & 13.5 & 10.8 \\
\hline VA96-44-304 & Hulled & 90.0 & 77.5 & 32.4 & 29.3 & 37.8 & 0.9 & 16.0 & 11.0 \\
\hline VA07H-35WS & Hulless & 75.0 & 65.0 & 34.3 & 24.6 & 38.8 & 3.3 & 18.0 & 14.3 \\
\hline VA04B-125 & Hulled & 95.8 & 68.3 & 35.8 & 20.4 & 45.2 & 0.6 & 23.8 & 8.5 \\
\hline Doyce & Hulless & 80.0 & 82.5 & 36.5 & 42.6 & 37.5 & 0.7 & 29.0 & 23.0 \\
\hline VA06H-25 & Hulless & 93.3 & 73.3 & 49.5 & 27.7 & 42.1 & 1.7 & 25.0 & 12.0 \\
\hline Mean & $\ldots$ & 70.6 & 65.6 & 23.8 & 21.2 & 24.5 & 0.9 & 15.8 & 10.0 \\
\hline Tukey's HSDz & $\ldots$ & 29.1 & 29.9 & 17.9 & 22.6 & 35.8 & 1.3 & 11.1 & 7.4 \\
\hline
\end{tabular}

${ }^{\mathrm{z}}$ Tukey's honestly significant difference (HSD). 
'Dan', and 'Atlantic' for marker ABG072 associated with QFhs.umn-2H.5 were identical to that of Fredrickson (414 and 273 bp, respectively). Fragment sizes amplified by the other six markers, especially those in resistant sources Nomini, Eve, and VA06H48, were not similar to those of Fredrickson, suggesting that QTL for FHB resistance in the Virginia Tech breeding program may be unique. Genotyping the Virginia Tech barley germplasm with SNP markers associated with FHB and DON resistance in CIHo 4196 produced similar results (Table 8; Supplementary Table S1). Haplotypes of the two resistance sources CIHo 4196 and Fredrickson are almost identical. Although the resistant genotypes Nomini, Eve, and VA06H-48 share some alleles in common with CIHo 4196 and Fredrickson, many of the alleles for markers associated with resistance in CIHo 4196 and Fredrickson differ in the Virginia Tech breeding program. Furthermore, many of the susceptible genotypes identified in the study, including Doyce and VA06H-25, have alleles in common with CIHo 4196 (Table 8). When comparing haplotypes of the Virginia Tech genotypes, a lack of polymorphism exists between the resistant genotypes Nomini, Eve, and VA06H-48 and susceptible genotypes Doyce and VA06H-25 for many of the markers. However, markers which differ between Eve, Doyce, and VA06H-25 serve as a starting point for identifying regions within the Virginia Tech germplasm which contribute to FHB and DON accumulation resistance. This suggests that QTL for FHB resistance in the Virginia Tech breeding program may be unique and highlights the need for further work to elucidate QTL

Table 6. Fragment size in base pairs (bp) for markers associated with quantitative trait loci (QTL) for Fusarium head blight (FHB) resistance on barley chromosomes $2 \mathrm{H}$ and $6 \mathrm{H}$ screened in Virginia Tech genotypes, known resistant genotype 'Chevron', and susceptible genotype 'Stander'

\begin{tabular}{|c|c|c|c|c|c|c|c|c|}
\hline \multirow[b]{3}{*}{ Genotype $^{\mathrm{z}}$} & \multicolumn{8}{|c|}{ QTL name and marker ${ }^{y}$} \\
\hline & \multicolumn{5}{|c|}{ Qrgz-2H-8 } & \multicolumn{3}{|c|}{ QTL 10} \\
\hline & EBmac0615 & Bmag0015 & GMS03 & GBM1023 & Bmac0132 & Bmag0807 & Bmag0870 & Bmag0613 \\
\hline Chevron & 197 & 181 & 146 & 246 & 186 & 117 & 117 & 167 \\
\hline Stander & 195 & 177 & 144 & 237 & NP & 122 & 122 & 161 \\
\hline Eve & 193 & 183 & 146 & 237 & NP & 121 & 118 & 165 \\
\hline VA06H-48 & 195 & NP & 144 & 238 & NP & NP & 117 & 163 \\
\hline Nomini & 193 & 183 & NP & 239 & NP & 119 & 116 & 161 \\
\hline VA06B-32 & 193 & 183 & NP & 237 & NP & 122 & 120 & 161 \\
\hline VA06H-31 & 193 & 183 & NP & 237 & NP & 124 & 116 & 172 \\
\hline Callao & 193 & 183 & NP & 237 & NP & 121 & 120 & 161 \\
\hline VA07B-52 & 193 & 183 & 146 & 239 & NP & 121 & 118 & 161 \\
\hline Thoroughbred & 193 & 183 & 146 & 237 & 186 & 118 & 118 & 161 \\
\hline Dan & 195 & NP & 144 & 239 & NP & 120 & 118 & 161 \\
\hline VA05H-59 & 195 & 183 & 144 & 237 & NP & 124 & 116 & 176 \\
\hline Atlantic & 194 & 183 & 146 & 237 & NP & 120 & 118 & 161 \\
\hline Price & 195 & 183 & 140 & 237 & 186 & 119 & 116 & 161 \\
\hline VA06H-142 & 196 & $\mathrm{NP}$ & NP & 237 & NP & 112 & 118 & 161 \\
\hline VA96-44-304 & 193 & 183 & 146 & 237 & NP & 119 & 118 & 161 \\
\hline VA07H-35 & 193 & 183 & 146 & NP & NP & 119 & 118 & 172 \\
\hline VA04B-125 & 193 & 183 & 146 & 238 & NP & 121 & 118 & 161 \\
\hline Doyce & 195 & NP & 144 & 237 & NP & 121 & 118 & 161 \\
\hline VA06H-25 & 193 & 183 & 146 & 237 & NP & 102 & NP & 172 \\
\hline
\end{tabular}

y Qrgz-2H-8 = QTL described by Nduulu et al. (28) for FHB severity (SEV), deoxynivalenol accumulation, and heading date on chromosome (chr.) 2H; and QTL $10=$ QTL described by Canci et al. (9) for FHB SEV and kernel discoloration on chr. 6H. Markers identify QTL in resistance source. NP $=$ no peak.

${ }^{\mathrm{z}}$ Chevron is a known resistant genotype for these markers and Stander is a known susceptible genotype described by Canci et al. (9).

Table 7. Fragment size in base-pairs (bp) for markers associated with quantitative trait loci (QTL) for Fusarium head blight (FHB) resistance on barley chromosome 2H screened in Virginia Tech genotypes and known resistant genotype 'Fredrickson'

\begin{tabular}{|c|c|c|c|c|c|c|c|c|}
\hline \multirow[b]{2}{*}{ Genotype $^{\mathrm{z}}$} & \multicolumn{8}{|c|}{ QTL name (marker) ${ }^{y}$} \\
\hline & $\begin{array}{c}\text { QDon.umn- } \\
\text { 2H.1 } \\
\text { (Bmag0125) }\end{array}$ & $\begin{array}{c}\text { QFhs.umn- } \\
\text { 2H.2 } \\
\text { (EBmac521a) }\end{array}$ & $\begin{array}{c}\text { QFhs.umn- } \\
\text { 2H.2 } \\
\text { (Bmag0140) }\end{array}$ & $\begin{array}{l}\text { QFhs.umn- } \\
\text { 2H.2 } \\
\text { (HVBKasi) }\end{array}$ & $\begin{array}{l}\text { QFhs.umn- } \\
\text { 2H.4/5 } \\
\text { (MWG882) }\end{array}$ & $\begin{array}{l}\text { QFhs.umn- } \\
\text { 2H.5 } \\
\text { (ABG072) }\end{array}$ & $\begin{array}{c}\text { QDon.umn- } \\
\text { 2H.1 } \\
\text { (Bmag0125) }\end{array}$ & $\begin{array}{c}\text { QFhs.umn- } \\
\text { 2H.2 } \\
\text { (EBmac521a) }\end{array}$ \\
\hline Fredrickson & 141 & 159 & 152 & 201 & 414 & 273 & 141 & 159 \\
\hline Eve & 119 & 163 & 160 & 182 & 414 & 273 & 119 & 163 \\
\hline VA06H-48 & 131 & 163 & 157 & 171 & 414 & 273 & 131 & 163 \\
\hline Nomini & 119 & 161 & 157 & 200 & 414 & 273 & 119 & 161 \\
\hline VA06B-32 & 131 & 163 & 161 & 201 & 414 & 273 & 131 & 163 \\
\hline VA06H-31 & 133 & 163 & 157 & 189 & 414 & 273 & 133 & 163 \\
\hline Callao & 131 & 163 & 159 & 201 & 414 & 273 & 131 & 163 \\
\hline VA07B-52 & 131 & 163 & 159 & 189 & 414 & 273 & 131 & 163 \\
\hline Thoroughbred & 131 & 163 & 157 & 202 & 414 & 273 & 131 & 163 \\
\hline Dan & 133 & 163 & 157 & 182 & 414 & 274 & 133 & 163 \\
\hline VA05H-59 & 133 & 163 & 157 & 183 & 414 & 273 & 133 & 163 \\
\hline Atlantic & 131 & 163 & 159 & 201 & 414 & 274 & 131 & 163 \\
\hline Price & 131 & NP & 159 & 201 & 414 & 273 & 131 & NP \\
\hline VA06H-142 & 133 & 163 & 155 & 184 & 414 & 273 & 133 & 163 \\
\hline VA96-44-304 & 153 & NP & 159 & 189 & 414 & 273 & 153 & NP \\
\hline VA07H-35 & 154 & NP & 157 & 201 & 414 & 273 & 154 & NP \\
\hline VA04B-125 & 131 & 163 & 159 & 201 & 414 & 273 & 131 & 163 \\
\hline Doyce & 133 & 163 & 155 & 143 & 416 & NP & 133 & 163 \\
\hline VA06H-25 & 131 & NP & 157 & 200 & 414 & 273 & 131 & NP \\
\hline
\end{tabular}

${ }^{\text {y }}$ QTL for FHB severity and deoxynivalenol accumulation described by Mesfin et al. (25) on chromosome 2H and marker identifying QTL in resistant genotype. $\mathrm{NP}=$ no peak.

${ }^{\mathrm{z}}$ Fredrickson is a known resistant genotype. 
for resistance in the resistant genotypes Nomini, Eve, and VA06H-48.

\section{Discussion}

With renewed interest in development of barley for traditional and new markets, research is needed to contribute to the improvement of barley genotypes. Although many diseases such as leaf rust (caused by Puccinia hordei), powdery mildew (caused by Blumeria graminis f. sp. hordei), net blotch (caused by Pyrenophora teres), and spot blotch (caused by Cochliobolus sativus) are important in the mid-Atlantic region (40), these pathogens do not produce mycotoxins which can accumulate in the grain and render it unmarketable. Damage caused by FHB manifests itself in reduced yields, discolored and shriveled kernels, mycotoxin contamination, and reduction in seed quality (27). Currently, the U.S. Food and Drug Administration (FDA) limits DON at $5 \mathrm{ppm}$ on grains and grain by-products which will be fed to swine (43). FDA limits for ruminating beef or feedlot cattle 4 months or older is $10 \mathrm{ppm}$ on grains and $30 \mathrm{ppm}$ in distillers dried grains (43). The current study evaluates a subset of winter barley genotypes previously classified as resistant, moderately susceptible, and susceptible to FHB (20). Testing across 2 years and two diverse locations in the current study was conducted to validate and further characterize FHB resistance levels and stability of these genotypes. This work is important because its goal is to confirm and further characterize FHB and DON resistance in winter barley germplasm. Validation of FHB phenotypes and analysis of genotypic data in winter barley in comparison with known sources of FHB resistance and QTL also facilitates development of mapping populations and deployment of marker-assisted breeding to further improve FHB resistance in barley. Therefore, the goal of this study was to address inconsistencies in FHB phenotypes and stability of resistance previously reported (20) or subsequently observed, and to further characterize FHB resistance in winter barley via analysis of genotypes using known markers for resistance QTL on chromosome $2 \mathrm{H}$ and $6 \mathrm{H}$.

The interaction between genotype and location was significant for FHB INC and IND, DON accumulation, and FDK, whereas the genotype-year interaction was only significant for FDK. Thus, in the current study, FHB development and epidemics were affected more by differences in endemic environmental conditions than by differences in environmental conditions between years. The geno- type-location interactions for FHB INC and IND, DON accumulation, and FDK can be attributed to a change in rank among moderately susceptible and susceptible genotypes resulting from differing levels of infection and DON accumulation between locations. In the current study, moderately susceptible and susceptible genotypes were those which had DON accumulation levels greater than $10 \mathrm{ppm}$ in Mt. Holly. Differences in average daily temperature and, to a lesser extent, daily precipitation between the two diverse locations likely contributed to this interaction and instability of genotype responses to FHB across locations. Environmental factors such as temperature and high humidity are important to FHB development in cereals (1). Average temperatures $\left(24\right.$ to $\left.29^{\circ} \mathrm{C}\right)$, extended periods of high humidity, and frequent rainfall provide the most favorable conditions for FHB development in cereals (19). It is likely that lower average daily temperatures at Blacksburg ( 13 to $23^{\circ} \mathrm{C}$ in 2010 and 13 to $21^{\circ} \mathrm{C}$ in 2011 ) versus those at Mt. Holly ( 17 to $27^{\circ} \mathrm{C}$ in 2010 and 17 to $25^{\circ} \mathrm{C}$ in 2011) hindered FHB infection and DON accumulation. The magnitude of FHB and DON accumulation under field conditions also is related to the amount and frequency of precipitation, humidity, or dew because FHB infection requires moisture $(27,31)$. Higher temperatures and humidity combined with daily precipitation at the nursery location in Mt. Holly likely contributed to increased FHB infection and development. Even though spray inoculations of macroconidia at flowering were applied in tests at Blacksburg as well as application of colonized corn kernels, FHB development was lower than at Mt. Holly, where only colonized corn kernel inoculums were applied to the tests. This further supports findings that temperature differences between the two locations had a major impact on FHB development.

Much debate has occurred regarding optimum timing of inoculation and rating for FHB resistance. FHB SEV and DON accumulation can increase in barley any time between heading and maturity (31). McCallum and Tekauz (26) observed that the optimal timing of inoculation appeared to be 14 days after heading, which best distinguished levels of susceptibility between genotypes. Often, INC and SEV are used as measures of resistance. In general, barley has varying levels of type I resistance (INC) and high innate levels of type II resistance (SEV) (38). Assessments of FDK in grain have been used as a measure of resistance to FHB and DON accumulation. DON accumulation was positively correlated with FDK

Table 8. Alleles for single nucleotide polymorphism (SNP) markers associated with quantitative trait loci (QTL) for Fusarium head blight resistance on barley chromosomes (Chr.) $2 \mathrm{H}$ and $6 \mathrm{H}$ in resistant and susceptible genotypes

\begin{tabular}{|c|c|c|c|c|c|c|c|c|c|c|}
\hline Marker ${ }^{v}$ & Chr.w & $\mathbf{c M}^{\mathbf{x}}$ & CIHo $4196^{y}$ & Fredrickson $^{y}$ & Chevron $^{y}$ & Stander $^{\mathrm{z}}$ & $\mathbf{E v e}^{\mathrm{z}}$ & VA06H-48 & Nomini ${ }^{y}$ & Doyce $^{z}$ \\
\hline 12_31474 & $2 \mathrm{H}$ & 58.5 & AA & AA & AA & AA & AA & $\mathrm{AA}$ & AA & $\mathrm{AA}$ \\
\hline 12_10650 & $2 \mathrm{H}$ & 84.96 & $\mathrm{AA}$ & AA & BB & $\mathrm{BB}$ & AA & AA & AA & AA \\
\hline 12_30674 & $2 \mathrm{H}$ & 85.52 & $\mathrm{AA}$ & AA & AA & AA & $\mathrm{BB}$ & $\mathrm{BB}$ & $\mathrm{BB}$ & $\mathrm{BB}$ \\
\hline 12_31445 & $2 \mathrm{H}$ & 90.48 & AA & AA & BB & BB & AA & AA & AA & AA \\
\hline 12_31095 & $2 \mathrm{H}$ & 133.04 & $\mathrm{AA}$ & $\mathrm{AA}$ & $\mathrm{BB}$ & $\mathrm{BB}$ & $\mathrm{BB}$ & $\mathrm{AA}$ & $\mathrm{AA}$ & $\mathrm{BB}$ \\
\hline 12_30636 & $2 \mathrm{H}$ & 138.04 & $\mathrm{BB}$ & BB & AA & AA & $\mathrm{BB}$ & BB & $\mathrm{AA}$ & AA \\
\hline 12_30396 & $2 \mathrm{H}$ & 151.92 & AA & AA & $\mathrm{AA}$ & BB & $\mathrm{BB}$ & $\mathrm{BB}$ & BB & $\mathrm{BB}$ \\
\hline 12_31233 & $6 \mathrm{H}$ & 3.46 & AA & AA & $\mathrm{AA}$ & $\mathrm{AA}$ & AA & $\mathrm{AA}$ & $\mathrm{AA}$ & AA \\
\hline 12_30842 & $6 \mathrm{H}$ & 20.62 & BB & BB & BB & $\mathrm{BB}$ & AA & AA & $\mathrm{AA}$ & AA \\
\hline 12_30516 & $6 \mathrm{H}$ & 46.44 & $\mathrm{BB}$ & BB & AA & $\mathrm{AA}$ & AA & $\mathrm{AA}$ & $\mathrm{AA}$ & $\mathrm{AA}$ \\
\hline 12_30317 & $6 \mathrm{H}$ & 49.67 & AA & AA & $\mathrm{BB}$ & $\mathrm{BB}$ & AA & BB & $\mathrm{BB}$ & AA \\
\hline 12_10199 & $6 \mathrm{H}$ & 49.67 & $\mathrm{BB}$ & BB & BB & BB & $\mathrm{BB}$ & AA & AA & $\mathrm{BB}$ \\
\hline 12_10910 & $6 \mathrm{H}$ & 52.19 & BB & BB & AA & AA & AA & BB & BB & AA \\
\hline 12_30569 & $6 \mathrm{H}$ & 55.31 & BB & BB & AA & AA & AA & $\mathrm{BB}$ & BB & AA \\
\hline 12_31178 & $6 \mathrm{H}$ & 60.65 & BB & BB & $\mathrm{BB}$ & AA & $\mathrm{BB}$ & $\mathrm{AB}$ & AA & AA \\
\hline 12_30144 & $6 \mathrm{H}$ & 61.19 & BB & BB & BB & $\mathrm{BB}$ & AA & BB & AA & AA \\
\hline ABC02895-1-4-231 & $6 \mathrm{H}$ & 65.51 & BB & BB & $\mathrm{BB}$ & AA & AA & AA & $\mathrm{AA}$ & AA \\
\hline 12_10758 & $6 \mathrm{H}$ & 65.83 & BB & BB & BB & $\mathrm{BB}$ & AA & BB & AA & AA \\
\hline 12_30346 & $6 \mathrm{H}$ & 65.83 & AA & AA & AA & AA & AA & AA & AA & AA \\
\hline 12_31111 & $6 \mathrm{H}$ & 83.28 & $\mathrm{AA}$ & $\mathrm{AA}$ & $\mathrm{AA}$ & AA & AA & AA & AA & AA \\
\hline $2298-1526$ & $6 \mathrm{H}$ & UNK & AA & AA & AA & BB & AA & AA & AA & AA \\
\hline
\end{tabular}

${ }^{v}$ SNP markers used for genotyping of the Virginia Tech winter barley germplasm.

${ }^{\mathrm{w}}$ Chromosome where marker was located.

${ }^{\mathrm{x}}$ Position on chromosome in centimorgans $(\mathrm{cM})$ where marker was mapped; UNK = unknown position.

${ }^{y}$ Resistant genotypes.

${ }^{\mathrm{z}}$ Susceptible genotypes. 
$(r=0.37, P \leq 0.01)$ at Blacksburg and highly correlated with FDK $(r=0.81, P \leq 0.001)$ at Mt. Holly. Jones and Mirocha (18) reported a significant positive correlation between visually scabby kernels (synonymous with FDK) and DON concentration.

Virginia Tech's barley program focuses on development of hulled and hulless cultivars and, thus, knowledge of variability for FHB resistance within and between these barley types is critical for breeding progress. In the current study, FHB INC and IND and DON accumulation did not differ significantly between hulled and hulless barley genotypes within the Virginia Tech program. Legzdina and Buerstmayr (22) also reported that the overall FHB mean, as measured by area under the disease progress curve, did not differ significantly between hulled and hulless genotype classes. However, they did report that DON accumulation of hulled barley was significantly higher than that of hulless barley.

Both hulled and hulless genotypes ranged from resistant to susceptible for FHB INC and IND and DON accumulation. Results of the current study validate the high level and stability of resistance to FHB and DON accumulation in Nomini and Eve winter barley and elite line VA06H-48. Similar levels of resistance were previously reported for Nomini and Eve (20). However, the putatively resistant genotype Thoroughbred (20) was moderately susceptible to susceptible to FHB in the current study across years and locations. In the previous study (20), Thoroughbred was rated over multiple years for FHB INC and IND and DON accumulation; however, only the FHB nursery in Blacksburg, VA was used as a test environment. Previously reported FHB INC and IND values for Thoroughbred were 7.5 to $50.0 \%$ and 1.0 to $12.3 \%$, respectively (20). In the current study, FHB INC values for Thoroughbred were 75.0 to $81.7 \%$ and IND values were 23.4 to $31.4 \%$. Similar to results presented for the Blacksburg environment in the current article, DON values reported by Khatibi et al. (20) were low $(<6$ $\mathrm{ppm}$ ) for all genotypes tested. Of the 10 genotypes tested from 2006 to 2010, DON values for Thoroughbred ranked sixth to tenth and were 0.3 to $6 \mathrm{ppm}$ (20). In the current study, DON values for Thoroughbred were $1.6 \mathrm{ppm}$ in Blacksburg to $30.5 \mathrm{ppm}$ in Mt. Holly. In the previous study (20) and in the current study, DON accumulation was low in the Blacksburg FHB nurseries. This may have led to the misclassification of FHB resistance levels in Thoroughbred in the previous study (20). It should also be noted that DON values reported in the previous study (20) were only significantly correlated with FHB INC and IND in 2006 and 2010. Inconsistencies among FHB and DON data from the Blacksburg scab nursery likely are due to the effects of the innately cooler temperatures and varying environmental conditions from year to year. If breeding assessments were made solely on data from the Blacksburg scab nursery, all genotypes would fall below 5 ppm for DON accumulation and be considered resistant. When grown in Mt. Holly, a different trend emerges and most genotypes have DON accumulations $>10 \mathrm{ppm}$ and are considered moderately susceptible to susceptible. Therefore, the environment in Blacksburg is not optimal in most years to clearly differentiate genotypes for FHB resistance or DON accumulation.

Currently, little is known about the genomic regions contributing to FHB resistance and DON accumulation in six-rowed winter barley. Differences in simple sequence repeat marker fragment sizes and SNP alleles in Virginia's FHB-resistant barley genotypes compared with those reported in other resistance sources $(9,25,28)$ suggests that unique QTL or alleles may be present in Virginia Tech's winter barley. A majority of resistance sources used in previous mapping studies, including Chevron, Fredrickson, 'Harbin' (CIHo 10620), and 'Zhedar 2', are of European or Asiatic origin $(11,12,25,34)$. With the exception of Chevron, resistance sources used in mapping studies are of the Vrs1 (two-rowed) phenotype. Crosses between Vrsl (two-rowed) and vrsl (sixrowed) phenotypes increase segregation and complicate the identification of resistant six-rowed material. Consequently, QTL contributing to FHB resistance in two-rowed $\times$ six-rowed populations frequently have been linked to the Vrs1 locus (25), which is of little value to those focusing on development of six- rowed genotypes. Although multiple genotypes evaluated in the current study amplified the same fragment size for markers identifying QFhs.umn-2H.5, further validation is needed to determine whether this QTL is present in Virginia Tech genotypes. Identification of additional FHB-resistant six-rowed material is of great value to breeding programs because few highly effective and diverse sources of resistance have been identified to date. This supports the need to develop mapping populations to find QTL and markers associated with regions contributing to FHB resistance and low DON accumulation in winter barley. Use of association mapping to identify marker-trait associations is becoming widely used within the barley research community. Massman et al. (24) used genome-wide association analysis to identify SNP markers associated with FHB resistance in a contemporary barley breeding programs which provides insight on similarity of regions of the barley genome between different resistance sources. Currently, mapping populations are being developed by the Virginia Tech barley breeding program from crosses of Nomini $\times$ Thoroughbred, Eve $\times$ Doyce, and Eve $\times$ VA07H-35WS. Populations developed from these crosses will be genotyped with SNP markers and association mapping will be used to identify regions of the genome contributing to FHB and DON accumulation resistance. Markers identified in future studies will hopefully be useful for MAS and be integrated into barley breeding programs.

\section{Acknowledgments}

This work was supported, in part, by grants to D. Schmale from the Virginia Small Grains Board (10278306) and the U.S. Wheat and Barley Scab Initiative (07185403), and to C. A. Griffey from the USWBSI (59-0790-4-102). We thank N. McMaster for her technical assistance in analyzing grain samples for DON and R. Horsley for access to his SNP marker set.

\section{Literature Cited}

1. Andersen, A. L. 1948. The development of Gibberella zeae headblight of wheat. Phytopathology, 38:595-611.

2. Berger, G., Liu, S., Hall, M., Brooks, W., Chao, S., Muehlbauer, G., Baik, B.-K., Steffenson, B., and Griffey, C. 2013. Marker-trait associations in Virginia Tech winter barley identified using genome-wide mapping. Theor. Appl. Genet. 126:693-710. Online publication. doi:10.1007/s00122-0122011-7

3. Brann, D. E., Holshouser, D. L., and Mullins, G. L. 2000. Agronomy handbook. Publ. no. 424-100, Virginia Coop. Ext. Blacksburg.

4. Brooks, W., Vaughn, M., Griffey, C., Price, A., Pridgen, T., Rohrer, W. Brann, D., Rucker, E., Behl, H., Sisson, W., Corbin, R., Kenner, J., Dunaway, D., Pitman, R., Premakumar, R., and Livingston, D. 2005. Registration of 'Thoroughbred' barley. Crop Sci. 45:789-790.

5. Brooks, W., Vaughn, M., Griffey, C., Price, A., Pridgen, T., Rohrer, W., Brann, D., Rucker, E., Behl, H., Sisson, W., Corbin, R., Kenner, J., Dunaway, D., Pitman, R., Premakumar, R., and Livingston, D. 2005. Registration of 'Price' barley. Crop Sci. 45:791-792.

6. Brooks, W., Vaughn, M., Griffey, C., Price, A., Pridgen, T., Rohrer, W., Brann, D., Rucker, E., Behl, H., Sisson, W., Corbin, R., Kenner, J., Dunaway, D., Pitman, R., Premakumar, R., and Livingston, D., Vivar, H., and Paris, R. 2005. Registration of 'Doyce' barley. Crop Sci. 45:792-793.

7. Brooks, W., Vaughn, M., Griffey, C., Thomason, W., Paling, J., Pitman, R., Dunaway, D., Corbin, R., Kenner, J., Hokanson, E., Behl, H., Beahm, B., Liu, S., Gundrum, P., Price, A., Brann, D., Whitt, D., Custis, J., Starner, D., Gulick, S., Ashburn, S., Jones, E., Jr., Marshall, D., Fountain, M., Tuong, T., Livingston, D., Premakumar, R., Kurantz, M., Taylor, F., Moreau, R., and Hicks, K. 2011. Registration of 'Dan' winter hulless barley. J. Plant Regist. 5:1-4.

8. Brooks, W., Vaughn, M., Griffey, C., Thomason, W., Paling, J., Pitman, R., Dunaway, D., Corbin, R., Kenner, J., Hokanson, E., Behl, H., Beahm, B., Liu, S., Gundrum, P., Price, A., Brann, D., Whitt, D., Custis, J., Starner, D., Gulick, S., Ashburn, S., Jones, E., Jr., Marshall, D., Fountain, M., Tuong, T., Livingston, D., Premakumar, R., Kurantz, M., Taylor, F., Moreau, R., and Hicks, K. 2012. Registration of 'Eve' winter hulless barley. J. Plant Registrations 6:5-11.

9. Canci, P., Nduulu, L., Muehlabuer, G., Dill-Macky, R., Rasmusson, C., and Smith, K. 2004. Validation of quantitative trait loci for Fusarium head blight and kernel discoloration in barley. Mol. Breed. 14:91-104.

10. Chen, J., Griffey, C. A, Saghai Maroof, M. A., Stromberg, E. L., Biyashev, R. M., Zhao, W., Chappell, M. R., Pridgen, T. H., Dong, Y., and Zeng, Z. 2006. Validation of two major quantitative trait loci for Fusarium head blight resistance in Chinese wheat line W14. Plant Breed. 125:99-101.

11. Dahleen L., Agrama, H., Horsley, R., Steffenson, B. J., Schwarz, P., Mesfin, A., and Franckowiak, J. 2003. Identification of QTLs associated with Fusarium head blight resistance in Zhedar 2 barley. Theor. Appl. Genet. 108:95-104. 
12. de la Pena R., Smith, K., Capettini, F., Muehlbauer, G., Gallo-Meagher, M., Dill-Macky, R., Somers, D., and Rasmusson, D. C. 1999. Quantitative trait loci associated with resistance to Fusarium head blight and kernel discoloration in barley. Theor. Appl. Genet. 99:561-569.

13. Griffey, C., Brooks, W., Kurantz, M., Thomason, W., Taylor, F., Obert, D., Moreau, R., Flores, R., Sohn, M., and Hicks, K. 2010. Grain composition of Virginia barley and implications for use in food, feed, and biofuels production. J. Cereal Sci. 51:41-49.

14. Ham, G. A, Stock, R. A., Klopfenstein, T. J., Larson, E. M., Shain, D. H., and Huffman, R. P. 1994. Wet corn distillers byproducts compared with dried corn distillers grains with solubles as a source of protein and energy for ruminants. J. Anim. Sci. 72:3246-3257.

15. Hori K., Kobayashi, T., Sato, K., and Takeda, K. 2005. QTL analysis of Fusarium head blight resistance using a high-density linkage map in barley. Theor. Appl. Genet. 111:1661-1672.

16. Hori K., Sato, K., Kobayashi, T., and Takeda, K. 2006. QTL analysis of Fusarium head blight severity in recombinant inbred population derived from a cross between two-rowed barley varieties. Breed Sci. 56:25-30.

17. Horsley R., Schmierer, D., Maier, D., Kudrna, D., Urrea, C., Steffenson, B.J., Schwarz, P., Franckowiak, J., Green, M., Zhang, B., and Kleinhofs, A. 2006. Identification of QTLs associated with Fusarium head blight resistance in barley accession CIho 4196. Crop Sci. 46:145-156.

18. Jones, R, and Mirocha, C. 1999. Quality parameters in smallgrains from Minnesota affected by Fusarium head blight. Plant Dis. 83:506-511.

19. Keller, M., Griffey, C., Lin, C., Scruggs, B., Stromberg, E., Thomason, W., and Schmale, D. 2012. Managing Fusarium head blight in Virginia small grains. Va. Coop. Ext. Serv. Publ. 3102-1535.

20. Khatibi, P., Berger, G., Liu, S., Brooks, W., Griffey, C., and Schmale, D. 2012. Resistance to Fusarium head blight and deoxynivalenol accumulation in Virginia barley. Plant Dis. 96:279-284.

21. Khatibi, P., Montanti, J., Nghiem, N., Hicks, K., Berger, G., Brooks, W., Griffey, C., and Schmale, D. 2011. Conversion of deoxynivalenol in barleyderived fuel ethanol co-products with yeast expressing tricothecene 3-Oacetyltransferases. Biotechnol. Biofuels 4:26-39.

22. Legzdina, L., and Buerstmayr, H. 2004. Comparison of infection with Fusarium head blight and accumulation of mycotoxins in grain of hulless and covered barley. J. Cereal Sci. 40:61-67.

23. Madson, P. W., and Monceaux, D. A. 1995. Fuel ethanol production. Pages 257-268 in: The Alcohol Textbook. T. P. Lyons, D. R. Kelsall, and J. E. Murtagh, eds. University Press, Nottingham.

24. Massman, J., Cooper, B., Horsley, R., Neate, S., Dill-Macky, R., Chao, S., Dong, Y., Schwarz, P., Muehlbauer, G. J., and Smith, K. P. 2010. Genomewide association mapping of Fusarium head blight resistance in contemporary barley breeding germplasm. Mol. Breed. 27:439-454.

25. Mesfin, A., Smith, K., Dill-Macky, R., Evans, C., Waugh, R., Gustus, C., and Muehlbauer, G. 2003. Quantitative trait loci for Fusarium head blight resistance in barley detected in a two-rowed by six-rowed population. Crop Sci. 43:307-318

26. McCallum, B., and Tekauz, A. 2001. Influence of inoculation method and growth stage on Fusarium head blight in barley. Can. J. Plant Pathol. 24:7780 .

27. McMullen, M., Jones, R., and Gallenberg, D. 1997. Scab of wheat and barley: a re-emerging disease of devastating impact. Plant Dis. 81:13401348 .

28. Nduulu, L., Mesfin, A., Muehlbauer, G., and Smith, K. 2007. Analysis of chromosome $2(2 \mathrm{H})$ region of barley associated with the correlated traits Fusarium head blight resistance and heading date. Theor. Appl. Genet. 115:561-570
29. O'Boyle, P. 2009. Genetic characterization and linkage mapping of barley net blotch resistance genes. Ph.D. dissertation, Virginia Polytechnic Institute and State University, Blacksburg.

30. Price, A., Griffey, C., Starling, T., Sisson, W., and Brann, D. 1996. Registration of 'Callao' barley. Crop Sci. 36:1077.

31. Prom, L., Horsley, R., Steffenson, B., and Schwarz, P. 1999. Development of Fusarium head blight and accumulation of deoxynivalenol in barley sampled at different growth stages. J. Am. Soc. Brew. Chem. 57:60-63.

32. Rudd, J., Horsley, R., McKendry, A., and Elias, E. 2001. Host plant resistance genes for Fusarium head blight: sources, mechanisms, and utility in conventional breeding. Crop Sci. 41:620-627.

33. Saghai Maroof, M. A., Soliman, K. M., Jorgensen, R. A, and Allard, R. W. 1984. Ribosomal DNA spacer-length polymorphisms in barley: Mendelian inheritance, chromosomal location, and population dynamics. Proc. Natl. Acad. Sci. USA 81:8014-8018.

34. Sato, K., Hori, K., and Takeda, K. 2008. Detection of Fusarium head blight resistance QTLs using five populations of top-cross progeny derived from wo-row $\times$ two-row crosses in barley. Mol. Breed. 22:517-526.

35. Schill, S. R. 2008. Beefing up barley. Ethanol Prod. Mag. October:78-84. http://ethanolproducer.com/

36. Schroeder, H. W., and Christensen, J. J. 1963. Factors affecting resistance of wheat to scab caused by Gibberella zeae. Phytopathology 53:831-838.

37. Starling, T., Griffey, C., Price, A., Roane, C., Sisson, W., and Brann, D. 1994. Registration of 'Nomini' barley. Crop Sci. 34:300.

38. Steffenson, B. J. 2003. Fusarium head blight of barley: impact, epidemics, management, and strategies for identifying and utilizing genetic resistance. In: Fusarium Head Blight of Wheat and Barley. K. J. Leonard and W. R. Bushnell, eds. American Phytopathological Society, St. Paul, MN

39. Steffenson, B. J., Prom, L. K., Salas, B., Fetch, T. G., Wesenberg, D. M and Bockleman, H. E. 1996. Severity of Fusarium head blight and concentrations of deoxynivalenol in near-isogenic lines of barley differing for several agronomic characters. Pages 774-776 in: Proc. 7th Intl. Barley Genet. Symp. A. Slinkard, G.Scoles, and B. Rosanagel, eds. University Extension Press, Saskatoon, Saskatchewan, Canada.

40. Stromberg, E. 2012. Disease and nematode management in field crops: small grains. Va. Coop. Ext. Publ. 456-016. http://pubs.ext.vt.edu/456/456016/Section 3 Diseases and Nematodes-4.pdf

41. Taketa, S., Amano, S., Tsujion, Y., Sato, T., Saisho, D., Kakeda, K., Nomura, M., Suzuki, T., Matsumoto, T., Sato, K., Kanamori, H., Kawasaki, S., and Takeda, K. 2008. Barley grain with adhering hulls is controlled by an ERF family transcription factor gene regulating a lipid biosynthesis pathway. Proc. Natl. Acad. Sci. USA 105:4062-4067.

42. Thomason, W., Brooks, W., Griffey, G., and Vaughn, M. 2009. Hulless barley seeding rate effects on grain yield and yield components. Crop Sci. 49:342-346.

43. U.S. Food and Drug Administration. 2013. Guidance for industry and FDA advisory levels for deoxynivalenol (DON) in finished wheat products for human consumption and grains and grain by-products used for animal feed. http:/www.fda.gov/Food/GuidanceRegulation/GuidanceDocumentsRegulat oryInformation/ChemicalContaminantsMetalsNaturalToxinsPesticides/ucm 120184.htm

44. Zar, J. H. 2010. Biostatistical Analysis, 5th ed. Pearson Prentice Hall, Upper Saddle River, NJ

45. Zhu, H., Gilchrist, L., Hayes P., Kleinhofs A., Kudrna, D., Liu, Z., Prom, L., Steffenson, B.J., Toojinda, T., and Vivar, H. 1999. Does function follow form? Principal QTLs for Fusarium head blight (FHB) resistance are coincident with QTLs for inflorescence traits and plant height in a doubled-haploid population of barley. Theor. Appl. Genet. 99:1221-1232. 